\title{
International Regulations for Preventing Collisions at Sea (COLREGs) amendment proposal
}

International Regulations for Preventing Collisions at Sea (hereinafter: COLREGs) should apply to all vessels. The term vessel is explained in Rule No. 3, defined as water craft, including non-displacement craft, wing-in-ground craft and seaplanes, used or capable of being used as a means of transportation on water. Regulations do not make any difference between large ships and small boats, regarding all of them as vessels. COLREGs are primarily intended for large vessels, applying also to smaller boats in an appropriate manner.

It is known that, for instance, sailing races (regattas) are regulated in detail, while the same cannot be claimed for COLREGs. If Regulations are applied to the encounter of two smaller boats or two large vessels of the same size, where there is risk of collision, speed and limitations can be considered quite clearly. From the aspect of good seamanship, this shouldn't represent an issue.

An issue emerges in case of the encounter of two significantly different vessels in size, speed and maneuvering characteristics (hereinafter: different vessels). This statement has been proven by the collision statistics referring to territorial waters and inland waterways of the Republic of Croatia. There was no case of a single collision between two large vessels in the past 15 years, while a significant number of collisions occurred in the period between two different vessels, as defined before.

It should be noted that the current COLREGs provides for the obligation of collision prevention between two different vessels and that part is straightforward. However, a problem appears where one vessel must avoid collision (COLREGs: action to avoid collision), while the other has to maintain its course and speed. The vessel which takes the action has to do so in a safe way implying passing at a safe distance from the other vessel. In case of different vessels, the term safe distance represents a major problem. Starting from their vessel's characteristics, any ship operator defines safe distance differently. A distance which is considered safe for a small vessel is far from safe in case of a larger vessel. 
Another problem occurring during collision avoidance is the effect of action taken to avoid collision. Namely, when a significantly slower vessel (compared to the other) has the obligation to avoid, the action to be taken as self-evident and enabling safedistance passing would take certain amount of time. On the other hand, a faster vessel can reach safe distance in a significantly shorter time.

As defined in Rule 1, paragraph b) and c) of the COLREGs, each state has the possibility to additionally arrange in its own discretion any additionally required provision.

In my opinion, national (Croatian) Regulations for Preventing Collisions at Sea in national territorial waters and inland waterways should be amended by the following:

1. The vessel underway making way through the water is required to avoid any anchored, berthed or grounded vessel;

2. The vessel underway not making way through the water is required to avoid any anchored, berthed or grounded vessel;

3. The vessel underway is required to avoid other vessel which is underway, when the latter vessel is five or more times longer;

4. In case that a vessel is three or more times faster than the other vessel, it has to take action of avoidance.

A brief explanation of proposed amendments:

Ad. 1: Anything making way through the water (whether by its own means or by the wind) is required to avoid what is stationary over the ground;

Ad. 2: The vessel being afloat without its propulsion and not making way through the water, but being carried by water towards another vessel that is stationary in relation to the ground, has to take action to avoid collision (by anchoring, employing oars, sails or engine, etc.);

Ad. 3: The number 'five' can be subject to discussion, however, the requirement for the smaller vessel to take action for prevention of collision with a significantly larger vessel should be defined and implemented accordingly;

Ad. 4: As in the preceding explanation, the suggestion of 'a three times faster vessel' can be subject to discussion and eventually be amended, but the faster vessel can much easier avoid a slower vessel, and therefore it should do so.

The whole conception of COLREGs provides for one vessel to take action while the other maintains its course and speed. According to the above-mentioned, it can happen that a larger vessel is also significantly faster. In that case, the smaller vessel should take action because of its size, while the larger one should prevent collision due to its speed. Therefore, both vessels should take appropriate actions. COLREGs' conception would be modified this way, however, we can state that its aim is to increase the safety of navigation. 